Coşgun Başar, M. ve Özmen, E. R. (2018). Bilgi veren metinleri anlama: Metin yapısına dayalı stratejilerin kullanımı. Ana Dili Eğitimi Dergisi, 6(4), 1179-1195.

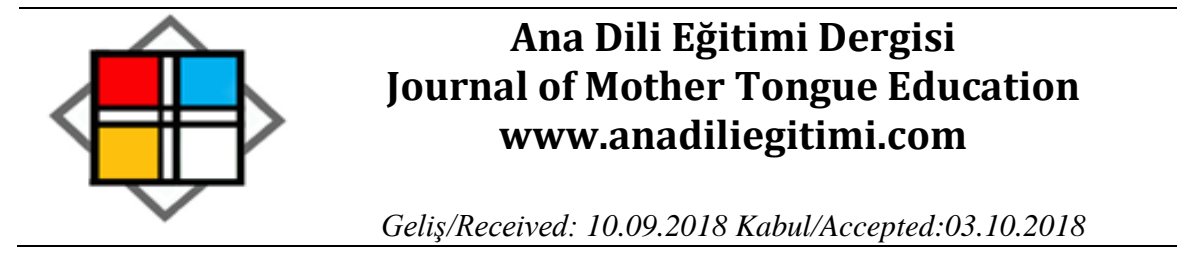

\title{
Bilgi Veren Metinleri Anlama: Metin Yapısına Dayalı Stratejilerin Kullanımı*
}

\author{
Mehtap COŞGUN BAŞAR ${ }^{* *}$ \\ E. Rüya ÖZMEN***
}

Öz

Okuma becerisine sahip olma, insanların bağımsız olarak bilgiye ulaşmalarında önemli faktörlerden biridir. Okumanın çözümleme ve anlama olarak iki bileşeni bulunmakta ve okuma becerisi bu iki bileşene dayalı olarak gelişmektedir. Bu bileşenlerden birinin sınırlı olması okuma becerisinin tam anlamıyla kazanılmadı̆̆ı anlamına gelmektedir. Anlama becerisinin karmaşık doğası ve yapılan araştırmalar yalnızca çözümleme becerisi kazanmanın anlama becerisinin kazanılması için yeterli olmadığını göstermektedir. Alan yazında, metin anlama becerisinin kazandırılmasında, metin yapısının öğretimine dayalı stratejilerin öğretimi dikkat çeken araştırmalar arasındadır. Bu çalışmada bilgi veren metinleri anlama becerisinin kazandırılmasında metin yapısı öğretiminin alt yapısını oluşturan Yapı-Bütünleştirme Modeli'nin kuramsal yapısının ve bu kuramsal çerçevede uygulamada kullanılan stratejilerin tanıtılması amaçlanmıştır.

Anahtar Kelimeler: okuma, metni anlama, metin yapısı, yapı-bütünleştirme modeli

\section{Comprehension of Expository Texts: Using Strategies Based on Text Structure}

\begin{abstract}
To have reading skills is one of the important factors in the independent access to information. There are two components of reading as decoding and comprehension, and reading skills are based on these two components. When one of these components is limited, it means that reading is not fully acquired. The complex nature of comprehension and the studies carried out indicate that acquiring only decoding skills is not enough to acquire comprehension skills. In the literature, the instruction of strategies based on the teaching of text structure is one of the most remarkable researches in the acquisition of text comprehension skills. In this study, it is aimed to introduce the theoretical structure of the Construction-Integration Model which constitutes the sub-structure of text structure teaching and the strategies used in practice in this theoretical framework in gaining expository text comprehension skills.
\end{abstract}

Keywords: reading, text comprehension, text structure, construction-integration model

\section{Giriş}

Metin anlama becerisini bilişsel bir süreç olarak ele aldığımızda, bu sürecin; algı, dil, dikkat, motivasyon, geçmiş bilgileri kullanma, çıkarım yapma gibi bileşenlerden oluştuğu ve asıl önemli noktanın bu bileşenlerin birlikte kullanılması olduğu alan yazında belirtilmektedir (Kintsch, 1988; Van

\footnotetext{
* Bu çalışma 11-14 Nisan 2018'de Ankara'da düzenlenen 17. Uluslararası Sınıf Öğretmenliği Sempozyumda sözlü bildiri olarak sunulmuştur.

${ }^{* *}$ Uzm. Etimesgut Özel Eğitim Meslek Okulu, Ankara, mehtapcosgunbasar@gmail.com

*** Prof. Dr. Gazi Üniversitesi, Gazi Eğitim Fakültesi, Ankara, ruyaozmen@hotmail.com
} 
den Broek, Virtue, Everson, Tzeng ve Sung, 2002). Her ne kadar anlama dediğimizde hepimiz benzer şeyleri anlasak da aslında anlamanın tam bir tanımını yapmak kolay değildir (Kintsch, 2013). Bu nedenle teoriler bağlamında anlamanın karmaşık doğasını çözmek ve bu teorilere bağlı olarak öğrencilere anlama becerisini öğretmek hâlâ güncelliğini korumaktadır. Bu bağlamda anlama öğretiminde etkili bir yöntem olan metin yapısına dayalı stratejilerin tanıtımı için öncelikle metin yapısına odaklanan Yapı-Bütünleştirme Modeli'nin (YBM) (Construction-Integration Model) dayandığı varsayımları ve YBM'ye göre metin anlamada rol alan bilişsel süreçleri açıklamak gerekmektedir.

\section{YBM’nin Dayandığı Varsayımlar}

1970'li yıllar psikologların okuma sürecine odaklandığı yıllar olmuş ve bir grup kuramcı metin özelliklerine/yapısına odaklanarak çalışmalarını yoğunlaştırmıştır (Pearson ve Cervetti, 2017). Bu çalışmalar sonucunda ortaya çıkan modellerden biri YBM olmuştur. Metin anlamanın altında yatan beceri ve süreçleri anlamamıza olanak sağlayan modeli (Clarke, Truelove, Hulme ve Snowling, 2014), Van Dijk ve Kintsch (1983) iki temel varsayıma dayalı olarak geliştirmiştir. Bu temel varsayımlardan birincisi bilişsel varsayım, ikincisi ise bağlamsal varsayımdır. Bilişsel varsayım kendi içerisinde üç varsayımı kapsamaktadır. Bunlar; yapılandırmacı, yorumlayıcı ve önvarsayımdır. "Yapılandırmacı" varsayıma göre insanlar olayları anlamak için görsel ve sözel verilere dayalı olarak belleklerinde zihinsel bir temsil yapılandırmaktadır. Örneğin; trafikte bir olaya tanık olan kişinin zihinsel temsili, trafik kazası olarak; kaza olayını bu kişiden dinleyen bir başka kişinin zihinsel temsili ise kaza hakkında hikâye olarak yapılanmaktadır. Bu durumda ikinci kişi yani kaza olayını dinleyen kişi zihninde var olan hikâye yapısına uygun olarak temsili yapılandırmaktadır. Bilişsel varsayım kapsamında yer alan ikinci varsayım "yorumlayıcı" varsayımdır. Zihinsel temsilin oluşmasında, görsel ve sözel verilerin yanı sıra insanların karşılaştıkları olaylar hakkında kendi yorumları da rol oynar. Olaya tanık olan kişi bu olayı kaza, -bir başka kişi kaza olmadığı şeklinde de yorumlayabilir- bu kazayı hikâye söyleminde (discourse) dinleyen kişi ise olayı kaza hakkında bir hikâye olarak yorumlar. Bilişsel varsayım kapsamındaki üçüncü varsayım ise "önvarsayımdır". Bu varsayıma göre insanların anlamlı bir zihinsel temsil oluşturabilmeleri için olaylar hakkında belli bir ön bilgiye sahip olmaları gerekir. Örneğin; bir olayı kaza olarak yorumlamak için trafik ve trafik ile bağlantılı konularda bilgi sahibi olmak gerekir. Bununla birlikte ön bilgilerin yanı sıra motivasyon, inanç, görüş, amaç ve tutumlar da olayların yorumlanmasında rol oynar. Kuramcılar bu bilişsel bilgileri "içsel veri" olarak adlandırmaktadır. Bu veriler anlama sürecini şekillendiren veriler olarak tanımlanabilir. Örneğin; bir metni ön yargılı okuduğumuzda çıkaracağımız anlam ile tarafsız olarak okuduğumuzda çıkaracağımız anlam farklı olacaktır ya da aynı metni okuyan iki kişinin metinden farklı anlamlar çıkarma olasılığı her zaman 
vardır. Bu durum, anlamanın -her insanın farklı içsel verilere sahip olmasından dolayı- kişiye özel bir eylem olduğu anlamını taşımaktadır.

YBM’nin dayandığı ikinci varsayım, bağlamsal varsayımdır. Bu varsayımın temelinde; anlama sürecinin yalnızca bilişsel değil aynı zamanda sosyal bir yönünün olduğu düşüncesi yatmaktadır. Diğer bir deyişle anlamada hem bilişsel hem de sosyal bağlamlar rol almaktadır ve bu ikisinin etkileşimi sonucunda anlama gerçekleşmektedir.

Bağlamsal varsayım çerçevesinde üç varsayım yer almaktadır. Bunlar; işlevsellik, pragmatik ve etkileşimci varsayımdır. "İşlevsellik" varsayımına göre hikâye gibi söylemler geniş bir sosyokültürel bağlam içerisinde üretilir ve yine bu geniş sosyokültürel bağlam içerisinde kişiler tarafından dinlenir/okunur. Dolayısıyla okuyan/dinleyen kişi kendi zihinsel temsilini bilişsel ve kendi sosyo kültürel bağlamına dayalı olarak oluşturur.

Bağlamsal varsayım kapsamındaki ikinci varsayım "pragmatik" varsayımdır. Bu varsayıma göre anlama sürecinde önemli bir diğer rolü yazarın/konuşmacının amacı oynamaktadır. Anlama sürecini bir iletişim süreci olarak tanımlayan modelde kişilerin anlamı yapılandırırken, kendi temsilleri -örneğin, hikâyeye ilişkin var olan temsili- ile yazarın/konuşmacının amacını eşledikleri varsayılmaktadır. Dolayısıyla birey okuduğu/dinlediği ile ilgili kendi zihinsel temsilini oluştururken aynı zamanda bu zihinsel temsil ile yazar ya da konuşmacının amacını eşler. Bu nedenle bireyin, yazarın hangi amaçla yazdığını fark etmesi, kendi zihinsel temsilini oluşturmasında etkili olur.

Bağlamsal varsayımlar içerisinde yer alan bir diğer varsayım ise "etkileşimci" varsayım olarak adlandırılmıştır. Bu varsayımda konuşma sürecine katılan kişilerin ya anlatan ve dinleyen olarak ya da okuma sırasında okuyucu ve yazar olarak etkileşim hâlinde oldukları ve zihinsel temsili sözel ya da sözel olmayan etkileşim sonucunda oluşturulduğu varsayılmaktadır. Bu bağlamda etkileşim sürecine katılan kişilerin benzer amaç, motivasyon ve niyette olmaları zihinsel temsilin oluşturulmasında rol oynamaktadır. Diğer bir deyişle, zihinsel temsilin oluşturulmasında okuyan/dinleyen kişinin amaç ve motivasyonunun yanı sıra anlatan/yazan kişinin amaç ve motivasyonu da etkili olmaktadır. Şekil 1'de YBM'nin dayandığı varsayımlar gösterilmiştir. 


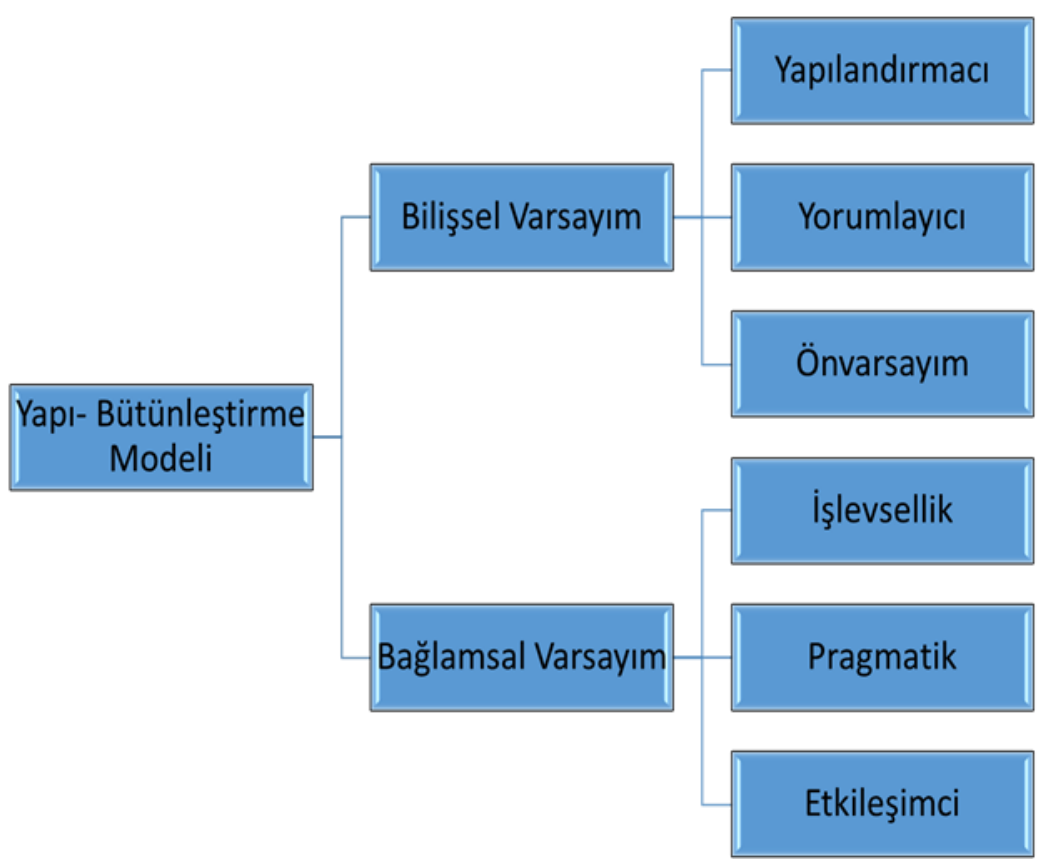

Şekil 1: YBM’nin dayandığı varsayımlar

YBM'yi bilişsel ve bağlamsal varsayım olmak üzere iki varsayıma dayalı olarak geliştiren Van Dijk ve Kintsch (1983) anlamanın yalnızca bilişsel bir süreç olmadığını aynı zamanda sosyal bağlam içerisinde gerçekleştiğini savunmaktadır. Bu nedenle kişinin zihinsel temsili oluşturmasında yazar ile okuyucunun etkileşimi ve bu etkileşimde amaç ve niyetin uyuşması önemli bulunmaktadır.

\section{YBM ve Metin Anlama}

Kintsch ve Van Dijk (1978) metin anlama, hatırlama ve özetleme süreçlerinin altında yatan zihinsel işlemleri tanımlamaya çalışmışlar ve metinlerde semantik yapıyı temel alarak anlama için zihinsel temsil oluşturma sürecini farklı bileşenlere ayırmışlardır. Bu modelin özelliklerinden biri, bazen ardışık bazen de paralel olarak ortaya çıkan çok sayıda bilişsel işlemi varsayıyor olmasıdır. Modele göre, zihinsel temsil oluşturma iki düzeyde gerçekleşmektedir (Kintsch ve Rawson, 2005; Van Dijk ve Kintsch 1983). İlk düzey metin tabanıdır. Semantik ve retorik yapısı ile okuyucuya anlama açısından önem taşıyan şifreli bir dizi ilişki sağlayan metin tabanı, Kintsch ve Rawson'a (2005) göre kişinin metnin anlamını yapılandırmasında rol oynamaktadır. Kişi bu düzeyde geçmiş bilgisi ile kişisel metin temsilini birleştirmektedir. Metin tabanını oluşturmanın önemli bir yönü, sözcük anlamlarını birleştirmek ve daha sonra metnin mikro yapısını oluşturmak için bu cümleler arasındaki karşıııklı ilişkileri kurmaktır.

Metin tabanı, yine kendi içerisinde üç düzeye ayrılmaktadır. Birinci düzey "dil” düzeyidir. Bu düzeyde kişi metinde yer alan sembolleri çözer. Metinde yer alan kelimeleri tanır, ayırt eder ve anlamlarını bilir ancak bu bilgi metni anlamak için yeterli değildir (Kintsch, 1998). İkinci düzey, "mikro yapı" olarak adlandırımıştır. Mikro yapı aynı zamanda lokal düzey olarak da adlandırılmaktadır. Bu 
Bilgi Veren Metinleri Anlama: Metin Yapısına Dayalı Stratejilerin Kullanımı

düzeyde kişi artık kelime ve cümleler üzerinde anlama işlemlerini gerçekleştirir. Kintsch'e (2013) göre bir metnin mikro yapısı metnin anlamını betimleyen cümleler ağıdır. Bu yapı bir nevi gerçek sözcüklerin bir fikre dönüştüğü düzeydir. Üçüncü düzey, "makro yapı" olarak adlandırılmıştır. Bu yapı aynı zamanda global yapı olarak da adlandırılmaktadır. Bir metni anlamak için metnin makro yapısının zihinsel bir temsilinin/şemasının oluşturulmasını gerektirmektedir. Örneğin bir hikâye makro yapısını, kurulum (örneğin, olayın nerede ve ne zaman geçtiği), düğüm (örneğin Ali'nin yağmurlu havada şemsiyesini almadan dışarıya çıkması) ve sonuç (örneğin, Ali'nin annesinin okul çıkışında şemsiye getirmesi ve Ali'nin ıslanmaması) oluşturur. Bu yapı, çocukların okulöncesi dönemden başlayarak öğrendiği bir yapıdır. Çocuklar okulöncesi dönemde dinledikleri hikâyelerle zihinlerinde bu yapının ögelerini oluştururlar ve bu yapının sırası zihinlerinde bir şema olarak yer alır. Makro yapılar genellikle şematik bir yapıya sahiptir. Ancak her makro yapı bir şemaya sahip olmak zorunda değildir. Mikro yapı ve makro yapı birlikte metin tabanının semantik temelini oluşturur (Kintsch, 2013).

Kısa bir metni anlamak için, okuyucu metinde geçen her bir kelimenin anlamını bilmesi, her bir cümle üzerinde işlem yapması, cümleleri birbiri ile bütünleştirmesi ve metnin zihinsel temsilini oluşturmak için bu bilgiler ile geçmiş bilgilerini bir araya getirmesi gerekmektedir (Cain ve Oakhill, 2009). Okuyucunun oluşturduğu bu temsile Kintsch (1998) Durum Modeli (Situational Model) adını vermiş̧ir. Zihinsel temsil oluşturmanın ikinci düzeyi olan Durum Modeli metnin sağladığı bilgi ile okuyucunun geçmiş bilgilerinin bütünleştiği düzeyi ifade etmektedir. Bu düzeyde metni daha derin anlamak için metin tabanından elde edilen bilgilerin yorumlanması gerekir. Okuyucuların oluşturduğu her bir Durum Modeli aslında kişinin okuma amacına, beklentilerine ve geçmiş bilgilerinin niceliğine göre değişmektedir. Durum Modelinde artık kişinin beklentileri, amaçları, geçmiş bilgileri rol oynamaya başlamaktadır. Diğer yandan okuyucu metin tabanına sahip olsa bile Durum Modeline sahip olmayabilir. Kintsch (2013) bunu "kapsüllenmiş" bilgi olarak adlandırmaktadır. Bunun anlamı okuyucunun metin tabanından elde ettiği bilgiyi Durum Modeli düzeyine geçirememesi yani metin tabanında elde ettiği bilgileri önceki bilgilerle birleştirerek yorumlayamaması anlamını taşımaktadır.

YBM, okuduğunu anlama sürecinin okunan metnin semantik ve retorik yapısı ile yakından ilişkili olduğunu savunmaktadır. Bu bağlamda, alan yazında kuramcılar ve araştırmacılar (Meyer, 1979; Williams, 2003) okuyucuların metin yazarlarının kullandığı yapıları takip etme becerisine sahip olmasının, metin anlamada önemli bir faktör olduğunu vurgulamaktadır. Bu nedenle alan yazın uygulamalarında öğrencilerin bilgi veren metinleri anlamalarında metin yapılarını ve öğrencilerin bu yapılar üzerinde çalışırken kullanabilecekleri stratejileri öğrenmeleri önemli noktaları oluşturmaktadır.

Şekil 2'de YBM'de bilginin işlenmesine ilişkin örnek görsele yer verilmiştir. 


\section{Dil}

Okuyucu, metni oluşturan kelimeleri tanır ve anlamları üzerinde işlem yapar.

Örneğin, metinde geçen "problem" kelimesi

Okur, bu kelimeye ilişkin "sorun, mesele" kelimelerini düşünür.

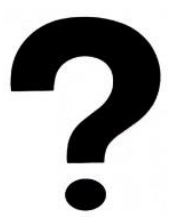

\section{Mikro yapı}

Okuyucu, kelimelerin ötesine geçerek metnin daha büyük parçaları, örneğin cümleler ya da cümlecikler üzerinde işlem yapar.

Örneğin, Günümüzün önemli problemlerinden biri heyelanlardır.

Okuyucu, metinde anlatılan problemin heyelan olduğunu anlar.

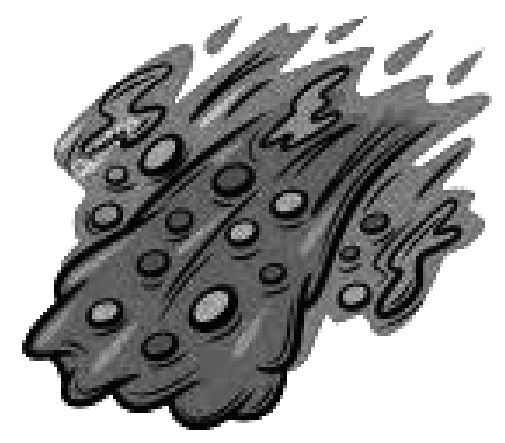

\section{Makro yapı}

Okuyucu, metindeki ana fikir, başlık ve metin türünü tanır ve işlem yapar.

Örneğin, Heyelanlar en çok Karadeniz Bölgesinde görülür.

Okuyucu, mikro yapı düzeyinde anladıklarını birleştirerek metnin, Karadeniz, heyelan ve doğa felaketi temalarına dayandığı sonucuna ulaşır. Okuyucu aynı zamanda metnin bilgi veren metin olduğunu anlar.
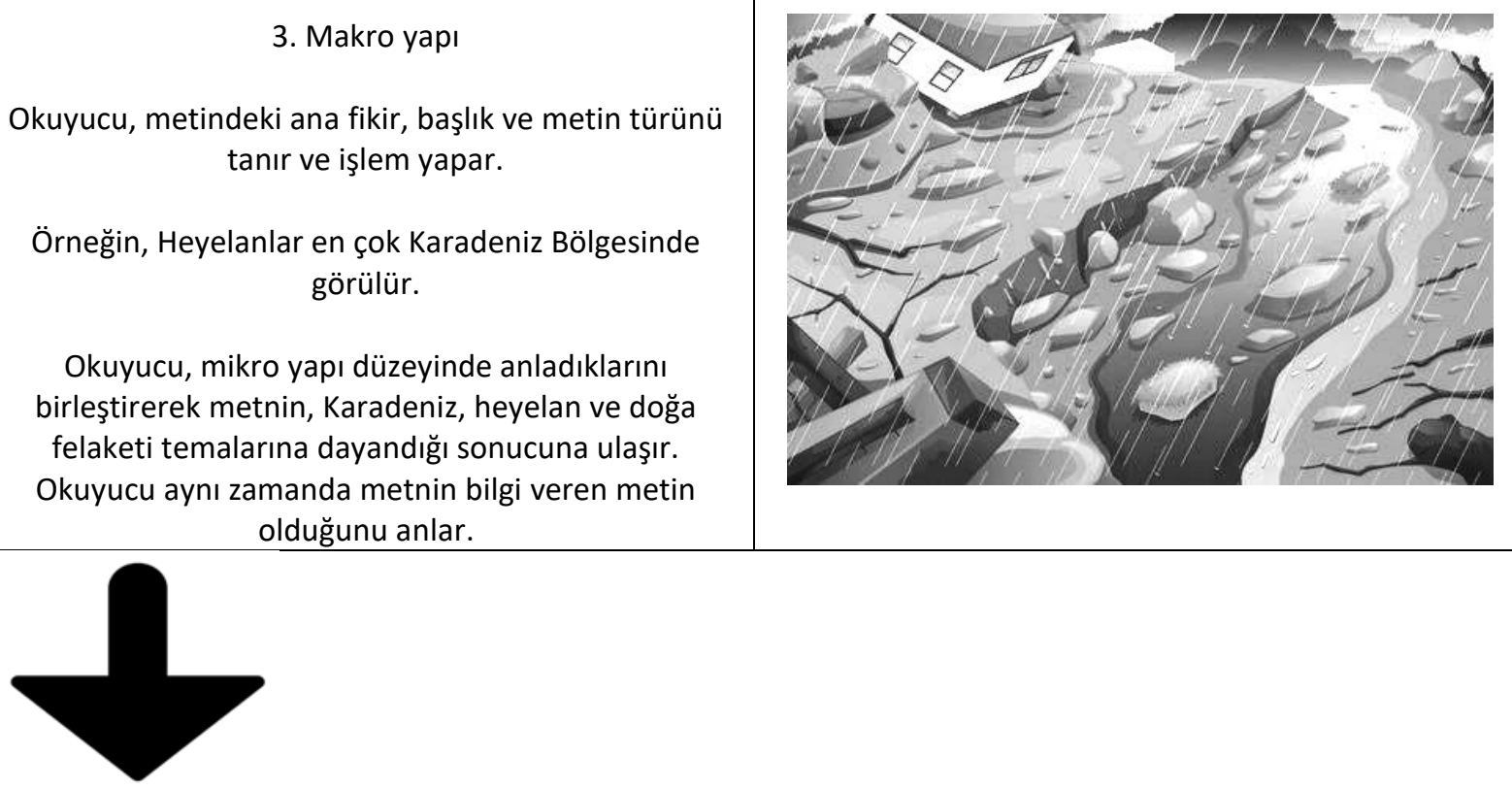


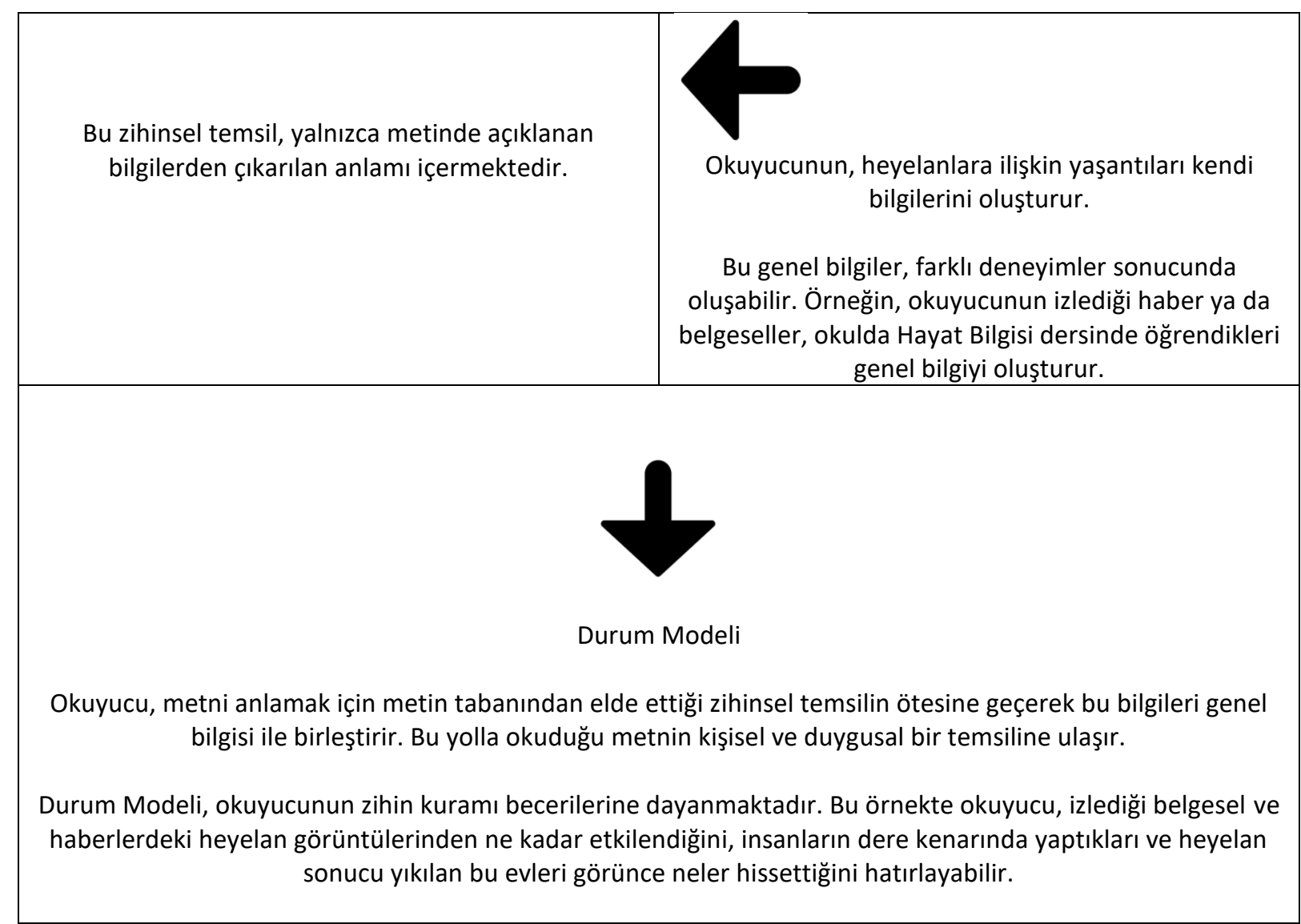

Şekil 2. YBM'de bilginin işlenmesine ilişkin uyarlanmış görsel

(Clarke, J. P., Truelove, E., Hulme, C ve Snowling M. J. (2014). Developing Reading Comprehension (s.6-7) kitabından uyarlanmıştır.)

\section{Bilgi Veren Metin Yapıları}

Kintsch'e (2013) göre zihinsel temsilin oluşturulmasında en önemli rolü metin yapıları oynamaktadır. Bir kavram olarak bilgi veren metin yapıları, okuyuculara rehberlik etmek için anahtar kelimelerin kullanılması ve metni oluşturan fikirlerin birbiriyle bağlanmasını içeren metin organizasyonlarıdır (Klingner, Vaughn ve Boardman 2007). Metin içerisinde açıkça belirtilmiş olan, örneğin, öncelikle, ikinci olarak, çünkü gibi anahtar kelimeler okuyuculara rehberlik edebilmekte ve bu anahtar kelimeler metnin hangi türde olduğu hakkında bilgi verebilmektedir. Bilgi veren metinler birçok farklı yapı ile yazılabilmektedir (Dymock, 2005). Armbruster, Anderson ve Ostertag (1987) bilgi veren metin yapılarını altı tür -tanımsal, sıralama, açıklama, karşılaştırma, neden-sonuç ilişkisi kurma ve problem/çözüm- olarak belirtmişlerdir.

Metin yapılarına ilişkin vurgulanması gereken önemli noktalardan biri oluşturulan yapıların bazı yönlerden değişmez özelliklere sahip olmasıdır. Diğer bir deyişle metin yapıları bir şablon gibi bilgilerin nasıl organize edileceği konusunda bize yol gösterir (Özmen, 2011). Bu nedenle bilgi veren metinler oluşturulurken amaca uygun olan yapı seçilmeli ve bu bilgiler yapının uygun olan kısımlarına yerleştirilmelidir. Böylece bir öğrenci örneğin, problem çözüm metnin yapısını öğrendikten sonra - 
konu ne olursa olsun- metinde anlatılan problemi, bu problemin nedenlerini ve çözüm yollarını nerede/hangi bölümde bulacağını öğrenmiş olur. Metin yapıları, öğrencilerin metni anlayabilmeleri ve hatırlayabilmeleri (Pearson ve Dole, 1987) için kılavuz niteliğindedir ve bu nedenle öğrencilere bu kılavuzu nasıl kullanmaları gerektiğini öğretmek önemlidir. Bu bağlamda aşağıda metin yapısı öğretiminin alt yapısını oluşturan YBM'nin kuramsal yapısı temel alınarak uygulamada kullanılan metin yapısı stratejilerin tanıtılması amaçlanmıştır.

\section{Metin Yapısına Dayalı Strateji Öğretimi}

Metin yapısına dayalı strateji öğretimi, yapıya uygun hazırlanmış bir metin üzerinde öğrencilerin yapı ögelerini tanımaları, metindeki bu önemli ögeleri bulmak için yapıya ait soruları öğrenmeleri ve metin yapısı hakkında öğrendikleri bu bilgileri stratejik olarak kullanmalarını içermektedir (Williams, 2005). Metin yapısı stratejileri öğrencilerin, metinde açık ya da dolaylı yoldan verilen bilgileri ve bu bilgilerin ilişkilerini anlamalarını sağlayan stratejilerdir (Meyer ve Ray, 2011). Bu bağlamda, metin yapısı stratejisini kullanan öğrenciler yazarın bilgi organizasyonunu diğer bir deyişle metin yapısını kendi anlamalarını düzenlemek için kullanırlar (Meyer, Brandt ve Bluth, 1980). Öğrencilere YBM'ye dayalı olarak metin yapılarını keşfetmelerine yardımcı olacak stratejilerin öğretimi ve bu stratejilerin öğrencilerin metin anlamalarındaki etkililiğinin incelenmesi, 1980'li yıllardan bu yana araştırmaların konusu olmuştur.

Günümüzde hâlâ güncelliğini koruyan araştırmalarda, metin yapısına dayalı strateji öğretiminin hem normal gelişim gösteren hem de farklı yetersizlik türlerine sahip öğrencilere metin anlama becerisi kazandırımasında etkili olduğu görülmektedir (Bakken, Mastropieri ve Scruggs, 1997; Carnahan ve Williamson 2013; Hall, Sabey ve Mcclellan, 2005). Sıklıkla ilkokul dönemindeki öğrencilerle (Armbruster ve ark. 1987; Wijekumar, Meyer ve Lei, 2012) ve sosyal bilgiler dersine ilişkin bilgi veren metinleri anlama öğretiminde (Alvermann, 1981; Hall ve ark. 2005; Meyer, Wijekumar ve Lin, 2011) kullanılan bu araştırmalarda, metinler öğretimi hedeflenen yapıya (örneğin, neden-sonuç metin yapısı vb.) uygun olarak hazırlanmıştır. YBM'de zihinsel temsilin oluşturulmasına hizmet eden metin yapıları, her bir araştırmada farklı metin türleri kendi belirli özelliklerine/yapılarına göre hazırlanarak kullanılmıştır. Bu araştırmaların öğretim süreçleri incelendiğinde ise; yapı öğretimi için birden fazla stratejinin bir arada kullanıldığı görülmektedir (Gaddy, Bakken ve Fulk, 2008; Willliams, Hall, Lauer, Stafford, DeSisto ve deCani, 2005; Williams, Stafford, Lauer, Hall ve Pollini, 2009). Bu bağlamda aşağıda metin yapısına dayalı strateji öğretiminde sıklıkla kullanılan stratejilere yer verilmiştir. 


\section{Metin Yapısı Tanıtımı}

Öğrencilerin metin yapıları hakkında bilgi sahibi olmaları onların bu yapıları bilgi edinmede nasıl kullanacaklarını öğrenmelerinde önemli bir adımdır (McGee ve Richgels, 1992). Bu nedenle öncelikle öğrencilere metin ve metin yapısı kavramlarını tanıtmak/anlatmak önemlidir. Öğrencilerin "metin" kelimesinin anlamını bilmeleri ve türlerini -kurgusal ve bilgi veren metin olarak- ayırt edebilmeleri onların hem metinle ilgili zihinsel temsili daha kolay oluşturmalarına hem de metin yazarlarının amaçlarını belirlemelerine hizmet eder. Öğrencilerin, yazarların metni hangi amaçla yazdıklarını bilmeleri, onların yazarın vermek istediği mesajı daha kolay anlamalarını sağlar (Meyer, 1987). Dolayısıyla yazar ile okuyucunun amaçlarının benzer olması anlama sürecine olumlu katkı sağlar.

Yazarların metinleri nasıl organize ettiklerini bilmek ve bu organizasyonu takip edebilmek önemli bir okuma becerisi olarak tanımlanmaktadır (Meyer, 1987). Yetkin okuyucular bir metnin başlığına ve alt başlığına bakarak metinde hangi konu hakkında bilgi verildiği ve bu konunun hangi alt başlıklarla detaylandırılığını belirleyebilirler (Williams, Hall ve Louer 2004). Yetkin olan okuyucuların bu becerisi otomatik olarak gerçekleşirken, okuma güçlüğü yaşayan öğrenciler için bu sürecin planlanması diğer bir deyişle stratejik bir davranış olarak öğrencilere metni nasıl gözden geçirecekleri ve bu gözden geçirme ile ne elde edeceklerini öğretmek gerekebilir. Bu gereklilik ile birlikte planlanan öğretim sürecinde, öğrenciler bir metne dair makro düzeyde nasıl bilgi edinebilecekleri -örneğin, başlık ile konu bilgisi ve alt başlıklar ile konunun nasıl detaylandırıldığı bilgisi-, elde ettikleri bu bilgilerin hangi soruların cevabı olduğu, -örneğin, “Metnin konusu ne?”, “Metinde hangi tema ve alt temalar var?"- ve metin türünü nasıl belirleyeceği ve böylece yazarın amacını nasıl tanımlayacağı bilgisini sağlayacaktır. Mikro düzeyde ise cümleler arasındaki bağlantıların nasıl kurulduğu, bu bağlantı kelimelerini nasıl belirleyecekleri ve paragraflar arasındaki ilişkileri nasıl fark edecekleri bilgisine sahip olacaklardır.

Öğrencilerin metin yapısına ilişkin keşifleri/bilgileri onların zihinlerinde bir yapı oluşmasında rol oynar. Dolayısıyla öğrencilerin okudukları bilgi veren metnin hangi yapı ile yazıldığını belirlemesi ve bu metin yapısına ait bilgisinin olması onların metin tabanında bilgileri daha kolay işlemeleri diğer bir deyişle zihinsel temsili daha kolay oluşturmalarını sağlayacaktır.

Öğrencilerin bilgi veren metin yapılarına ilişkin öğrenmeleri gereken bir başka nokta ise yapı bölümlerinin metin içerisinde nasıl sıralandığıdır. Bunun için; öğretimde hatalı sırada oluşturulan ya da bir bölümü eksik olan metin örnekleri üzerinde çalışılabilir ve yapıda bulunan hataların/eksiklerin öğrencilerle birlikte tespit edilmesi gibi etkinliklere yer verilebilir. Böylece öğrenciler yapı içerisindeki 
bölümlerin sıralanışını ve birbiri ile olan bağlantısını görebilir ve metne ilişkin zihinsel bir yapı oluşturabilirler.

\section{Anahtar Kelimeler}

Araştırmalarda çoğunlukla öğrencilere, metin yapısı öğretiminde kritik bir yeri olan anahtar kelimeler (Meyer ve ark. 2011; Smith ve Friend, 1986; Spires, Gallini ve Riggsbee, 1992; Weisberg ve Balajthy, 1989; Wijekumar ve ark. 2012) ve bu kelimelerin metin içerisindeki işlevleri ile onları stratejik olarak nasıl fark edecekleri/belirleyecekleri öğretilmiştir. Anahtar kelimeleri tanıma öğrencilerin mikro düzeyde bilgilerin nasıl bağlandığını görebilmeleri adına önemli bir stratejidir.

Van Dijk ve Kintsch'e (1983) göre metin içinde yer alan bilgilerin tutarlılığı, anlama için önemli bir faktördür. Tutarlı bir metin, okuyucunun metinde geçen olaylar arasında bağlantı kurmasını sağlamasına yardımcı olur. Böylece öğrenciler mikro düzeyde olayların bağlantısını daha kolay kurabilir. Okurların, metindeki bilgileri birbiri ile bağlamasını sağlayan noktalar ise "çünkü, neden, önce, sonra vb." anahtar sözcüklerdir. Bu sözcükler bir nevi metinde geçen olay ya da bilgiler arasında ilişki kurmamızı sağlayan doğal işaretlerdir. Bu işaretlerin kullanılması tutarlı bir metin oluşturmak için kritik öneme sahiptir (Degand ve Sanders, 2002).

Okuyucuların cümleler arasında uygun bağları kurmaları, onların elde ettikleri bilgileri daha iyi belleklerinde tutmalarına ve olaylar arasında açıç̧a belirtilmeyen ilişkiler hakkında çıkarım yapmalarına da izin verir (Ferstl ve von Cramon, 2001). Bilgi veren metinlerin yazımı sırasında yapıyı oluşturmak diğer bir deyişle bilgiler arasındaki bağlantı noktalarını sağlamak için anahtar kelimeleri kullanmak önemlidir.

Okurun metin yapısına ilişkin bilgisi ve anahtar kelimeleri fark etmesi, bilgileri hızlı bir şekilde kullanarak belleğinde var olan bilgiler ile yeni bilgileri birleştirerek yeniden yapılandırmasına yardımcı olur. Dolayısıyla tutarlı bir metin yapısı anlama için rehber görevini görür (Oakhill, Cain ve Elbro, 2014). Bununla birlikte McNamara ve Kintsch'e (1996) göre metnin konusu hakkında yeterli geçmiş bilgisi olmayan okurlar metni anlamak için bilgiler arasında bağlantı sağlayan anahtar kelimelerden daha fazla faydalanır. Örneğin, sıralama metinlerinde, önce ve sonra bağlaçları bize zamansal bir sıra verir. "Ordular önce güneye ilerlerdi sonra batıya." cümlesinde olduğu gibi bağlaç kullanımı okuduğumuz olaylarla ilgili sıralamayı anlamamızı kolaylaştırır. Bununla birlikte bağlaçların yer değiştirmesi durumunda, yani "önce" kelimesinin yerine "sonra" kelimesi getirildiğinde cümlenin anlamı tamamen değişime uğrar. Öğrencilere anahtar kelimelerin öğretimi sırasında, kelime anlamlarını sözlükten araştırtmak, tek bir anahtar kelimenin yer aldığı cümle kurmalarını istemek, anahtar kelime kullanılan cümleleri anahtar kelime kullanılmayan cümleler içinden ayırt etmek ya da bir paragraf içerisinde anahtar kelimeyi belirlemek gibi etkinliklere yer verilebilir. 


\section{Şematik Düzenleyiciler}

Metin yapısı öğretimine ilişkin yapılan araştırmaların öğretim süreçleri incelendiğinde karşımıza sıklıkla çıkan bir başka strateji ise şematik düzenleyicilerin kullanımıdır (Alvermann, 1981; Williams, Hall, Lauer, Stafford, DeSisto ve deCani, 2005; Williams, Nubla-Kung, Pollini, Stafford, Garcia ve Snyder, 2007). Ausubel (2002) şematik düzenleyicileri "gelişmiş düzenleyici" olarak adlandırmış ve bu düzenleyicilerin öğrencilerin önceki bilgileri ile yeni öğrendikleri bilgileri bütünleştirmelerini sağlayan pedagojik araçlar olarak tanımlamıştır. Bilgi veren metinlerin öğretimi sırasında öğrencilerin öğrenme deneyimini desteklemek için kullanılabilecek önemli araçlardan biri olan şematik düzenleyiciler (Martins, 2002), öğrencilerin zihinlerinde oluşturdukları metin yapılarını somutlaştırmalarında diğer bir deyişle metin yapısını görmelerine yardımcı olmaktadır (Pressley, 2002; Özmen, 2011). Ülkemizde yapılan çalışmalarda kurgusal metin türlerinden hikâye yapılarının öğretiminde şematik düzenleyiciler yaygın olarak kullanılmaktadır (Duman ve Tekinarslan, 2007; Işıkdoğan ve Kargın, 2010; Yazıcı, 2006). Ausubel (2002), kurgusal metinlerin aksine öğrencilerin aşina olmadığı bilgi veren metinlerde şematik düzenleyicilerin eski ve yeni bilgileri bütünleştirdiğini ve birbirine benzeyen ama farklılık barındıran yeni bilgi ile var olan geçmiş bilgi arasında ayrım yapmalarına da olanak sağladığını vurgulamaktadır. Bu nedenle öğrenciler metin yapılarını ve şematik düzenleyicileri tanıdıktan sonra bu şemaları kendi başlarına nasıl kullanacakları öğretilmelidir.

\section{Özetleme}

Metin anlama öğretiminde kullanılan önemli stratejilerden bir diğeri olan özetleme; ilgisiz/ayrıntı bilgilerin dışarıda bırakılarak, önemli ve benzer bilgilerin bir araya getirilmesi ile metindeki ana fikrin ve ona bağlı bilgilerin yazılı ya da sözlü olarak ifade edilmesi olarak tanımlanabilir (Block ve Pressley, 2002). Özetlemede öğrenciden beklenen okuduğu metinde önemli bilgileri ayırt ederek bu bilgileri kendi cümleleri ile yazması ya da anlatmasıdır. Diğer bir deyişle öğrencinin metin içerisindeki bilgileri analiz etmesi, ayırması, seçmesi (Klingner ve ark. 2007; Westby, Culatta, Lawrence ve Hall-Kenyon, 2010) ve yalnızca önemli bilgileri kendi cümleleri ile ifade etmesidir.

Metin yapısına dayalı strateji öğretiminin yapıldığı araştırmalarda özetleme stratejisinin öğretimi için öğrencilere farklı desteklerin sunulduğu görülmektedir (Carnahan ve Williamson 2013; Williams, 2005; Williams, 2014). Bunlardan biri özetleme şablonlarıdır (Paragraph Frame, Templates). Özellikle yazma becerisinin geliştirilmesine ihtiyaç duyan öğrenciler için kullanılması önerilen (Harris ve Graham, 1996) özetleme şablonları öğrencilerin özetleme becerisini -metin yapısına dayalı olarakdestekleyen etkinliklerden biridir. Özetleme şablonları bir metin içerisinde, metne ilişkin anahtar kelimelerin ve anahtar cümlelerin verildiği ancak önemli bilgilerin eksik bırakıldığı form olarak tanımlanabilir. Öğrencilerden özetleme için şablon içerisindeki boşluklara hatırladıkları önemli 
bilgileri yine yapıya ilişkin bilgilerinden yararlanarak yazmaları beklenir. Öğrencilerden bu şablon ile özetlemede deneyim kazandıktan sonra herhangi bir ipucu sunulmadan, boş bir kâğıda kendi başlarına özetleme yapmaları istenir. Öğrencilere özetleme yapmalarında yardımcı olan bir diğer strateji yapı sorularıdır. Özet yazarken öğrencilere rehberlik eden yapı soruları (Carnahan ve Williamson, 2013) öğrencilerin önemli bilgilere odaklanmalarına ve böylece özetleme için hangi bilgileri kullanmaları gerektiğine karar vermelerine yardımcı olur. Diğer yandan bu sorular, öğrencilere cevapları metnin hangi bölümünde aramaları gerektiğini düşünmelerine hizmet eder (Williams, 2005). Örneğin öğrenciler tanımsal türde bir metin üzerinde çalışırken kendilerine; "Metinde hangi konuda bilgi verilmiştir?", "Konunun hangi özellikleri anlatılmıştır?" gibi sorular yöneltmesi onların önemli bilgileri ayırt etmelerini sağlayacaktır. Bu bağlamda, öğrencilerin metin üzerinde çalışırken yapı sorularını stratejik olarak nasıl kullanacaklarını öğrenmeleri metnin zihinsel temsilini oluşturmalarını sağlayarak onların önemli bilgileri ayırt etmelerine ve bu yolla özetleme becerisini kazanmalarına hizmet edecektir. Tablo $1^{\prime}$ de metin yapısı öğretimine ilişkin aşamalara ve etkinliklere örnek verilmiştir.

Tablo 1. Metin yapısı öğretim aşamaları ve yapılabilecek etkinlikler

\section{Metin Yapısı Öğretimi Aşamaları}

Metin türlerinin tanıtımı

Bilgi veren metin türünü tanıtma

Bilgi veren metin türüne ilişkin kullanılan anahtar kelimeleri tanıtma

Bilgi veren metin türünün ögelerini ve metin içerisinde sıralanışını tanıtma

Bilgi veren metin türünün olumlu ve olumsuz örneklerini ayırt etme

Yapı sorularını tanıtma

Şematik düzenleyiciyi tanıtma

Metin analizi

Özetleme

\section{Yapılacak Etkinlikler}

Metin türlerinin -kurgusal ve bilgi veren türde metin olarak- ve ayırt edici özelliklerinin tanıtımı, metin türlerinin okul dersleri ile bağlantıları ve amaçları üzerine tartışma.

Üzerinde çalışılacak olan bilgi veren metin türünü ve genel özelliklerini tanıtma.

Üzerinde çalışılacak metne ait anahtar kelimeleri tanıtma, bu kelimeleri örnek cümleler üzerinde belirleme, okunan cümlelerin anlamları üzerinde tartışma.

Üzerinde çalışılacak metnin bölümleri ve bu bölümlerin metin ile ilgili hangi bilgileri sağladığı üzerine tanıtım/tartışma

Yapıya uygun yazılan ve yazılmayan metinleri ayırt etme.

Üzerinde çalışılacak metin yapısı sorularını tanıtma, bu soruların cevaplarını metnin hangi bölümünde bulabileceğimiz üzerine tartışma

Üzerinde çalışılacak metne ait şematik düzenleyiciyi tanıtma/şekil üzerine tartışma

Metnin okunması sırasında anahtar kelimelerin bulunması, anahtar kelimelerle elde edilen bilgilerin tartışılması ve bu bilgilerin şematik düzenleyicide ilgili bölüme yerleştirilmesi

Şematik düzenleyiciden yararlanarak metnin özetlenmesi 
Yapılan araştırmalarda kullanılan bu stratejiler ile öğrencilerin metin yapılarını öğrendikleri ve bu yol ile bilgi veren metinleri anlamalarında gelişme olduğu belirlenmiştir (Bakken ve ark. 1997; Carnahan ve Williamson 2013; Hall ve ark. 2005; Williams ve ark. 2007). Ülkemizde ders kitapları incelendiğinde metin yapısı öğretiminin hikâye türü metinlerle ve hikâye haritası tekniği ile sınırlı kaldığı görülmektedir. Hikâye yapısına ilişkin ögelerin ve bu ögelerin birbirleri ile olan ilişkilerini göstermek için kullanılan (Idol, 1987) hikâye haritalarında amaç, öğrencilerin hikâye yapılarını kendi zihinlerinde bu şema yardımı ile oluşturabilmeleridir. Ülkemizde yapılan araştırmalar bağlamında da aynı sınırılıklar göze çarpmaktadır. Bu araştırmalara genel olarak bakıldığında metin türü olarak hikâyelerin kullanıldığı ve hikâye haritası öğretim tekniğine yer verildiği görülmektedir (Duman ve Tekinarslan, 2007; Işıkdoğan ve Kargın, 2010; Yazıcı, 2006; Yılmaz, 2008). Metin yapılarının öğretiminde şemaların kullanımı önemli bir strateji olmakla birlikte, yapılan araştırmalarda şema kullanımının yanı sıra farklı stratejilere de yer verilmesinin, öğretim sürecini destekleyeceği ve dolayısıyla metin anlamayı güçlendireceği düşünülmektedir.

Temelde metin anlama için zihinsel temsilin oluşmasına ve oluşan bu zihinsel temsil ile öğrencinin genel bilgisinin bütünleşmesine dayanan modele ilişkin yapılan araştırmalarda, öğrencilere yazarların bilgi organizasyonlarını diğer bir deyişle metin yapılarının keşfetmelerine yönelik geliştirilen stratejiler öğretilmiştir. Metin türlerini ayırt etme, yapı tanıtımı, anahtar kelimeleri tanıma, terimlerin anlamlarını bulma, şematik düzenleyicilerin kullanımı, yapı sorularını cevaplama ve özetleme gibi öğrencilerin dil, mikro ve makro düzeyde bilgi elde etmelerini sağlayan bu stratejiler ile öğrencilerin metin yapılarını öğrendikleri ve buna bağıı olarak metin anlama düzeylerinde gelişme olduğu belirlenmiştir.

Sonuç olarak, hem normal gelişim gösteren hem de yetersizlikten etkilenmiş öğrencilerin metin anlama becerilerinde gelişme sağlayan bu stratejilerin ülkemizdeki öğretmenler tarafından kullanılması ve bilim insanlarının bu alana ilişsin daha fazla bilimsel çalışma yapması önemli görülmektedir.

\section{Kaynaklar}

Alvermann, D.E. (1981). The compensatory effect of graphic organizers on descriptive text. The Journal of Educational Research, 75(1), 44-48.

Armbruster, B. B., Anderson, T. H. ve Ostertag, J. (1987). Does text structure/summarization instruction facilitate learning from exprository text. Reading Research Quarterly, 22 (3), 331-346.

Ausubel, P. D. (2002). The Acquisition and Retention of Knowledge: A Cognitive View. Springer Science+Business Media B.V. 
Bakken, J. P., Mastropieri, M. A. ve Scruggs, T. E. (1997). Reading comprehension of expository science material and students with learning disabilities: A comparison of strategies. The Journal of Special Education, 31 (3), 300-324.

Block, C. C. ve Pressley, M. (2002). Comprehension instruction: Research-based best practices (s. 42-61). New York: Guilford Press.

Cain, K. ve Oakhill, J. (2009). Reading Comprehension Development from 8 to 14 Years: The Contribution of Component. Skills and Processes. Wagner, R. K., Schatschneider, C. ve Phythian-Sence, C. (Ed.) içinde, Beyond Decoding: The Behavioral and Biological Foundations of Reading Comprehension. (s.143-176), The Guilford Press. NY.

Carnahan R. C. ve Williamson, P. S. (2013). Does compare-contrast text structure help students with autism spectrum disorder comprehend science text. Council for Exceptional Children, 79 (3), 347-363.

Clarke, P. J., Truelove, E., Hulme, C. ve Snowling, M. J. (2014). Developing Reading Comprehension. Wiley Blackwell. John Wiley ve Sons, Ltd. UK.

Degand, L. ve Sanders, T. (2002). The impact of relational markers on expository text comprehension in L1 and L2. Reading and Writing, 15, 739-757.

Duman, N. ve Tekinarslan, i. (2007). Hikâye haritası yönteminin hafif düzeyde zihinsel yetersizliği olan öğrencilerin okuduğunu anlama becerileri üzerindeki etkisi. Ankara Üniversitesi Eğitim Bilimleri Fakültesi Özel Eğitim Dergisi, 8 (1) 33-55.

Dymock, S. (2005). Teaching expository text structure awareness. The Reading Teacher, 59 (2), 177-181.

Ferstl, E. C. ve von Cramon, D. Y. (2001). The role of coherence and cohesion in text comprehension: an eventrelated fMRI study. Cognitive Brain Research, 11, 325-340.

Gaddy, A. S., Bakken, J. P. ve Fulk, M. B. (2008). The effects of teaching text-structure strategies to postsecondary students with learning disabilities to improve their reading comprehension on expository science text passages. Journal of Postsecondary Education and Disability, 20 (2), 100-119.

Hall, K. M., Sabey, B. L. ve McClellan, M. (2005). Expository text comprehension: Helping primary-grade teachers use expository texts to full advantage. Reading Psychology, 26, 211-234.

Harris, K. R. ve Graham, S. (1996). Making the writing process work: Strategies for composition and selfregulation. Cambridge, MA: Brookline Books.

Idol, L. (1987). Group story mapping: A comprehension strategy for both skilled and unskilled readers. Journal of Learning Disabilities, 20(4), 196-205.

Işıkdoğan, N. ve Kargın, T. (2010). Hikâye haritası tekniğinin zihin engelli öğrencilerin okuduğunu anlama becerilerini kazanmalarındaki etkililiği. Kuram ve Uygulamada Eğitim Bilimleri, 10 (3), 1489-1531.

Kintsch, W. ve van Dijk, T. A. (1978). Toward a model of text comprehension and production. Psychological Review, 85 (5), 363-394.

Kintsch, W. (1988). The role of knowledge in discourse comprehension: a construction-Integration model. Psychological Review, 95 (2),163-182.

Kintsch, W. (1998) Comprehension: A paradigm for cognition. New York: Cambridge University Press.

Kintsch, W. ve Rawson, K. A. (2005). Comprehension. Snowling M. J. ve Hulme C. (Ed.) içinde, The science of reading: A handbook (s. 209-26). Oxford: Blackwell.

Kintsch, W. (2013). Revisiting the construction-integration model of text comprehension and its implications for instruction. Alverman, D. E., Unrau, N. J., Ruddell, B. R. (Ed.) Theoretical Models and Procesess of Reading. (6th ed.), (s. 807-839). Newark, DE: International Reading Association.

Klingner, J. K., Vaughn, S. ve Boardman, A. (2007). Teaching reading comprehension to students with learning disabilities. New York, NY: Guildford Press 
Martins, I. (2002). Visual imagery in school science text. Otero, J., León, J. A ve Graesser, A. C. (Ed.) içinde, The Psychology of Science Text Comprehension. Mahwah, N.J. : L. Erlbaum Associates, 73-91.

McGee, M. L. ve Richgels, D. J. (1992). Text structure strategies. E.K., Bean, T.W., Readence, J.E., Moore, D.W. (Ed.) içinde, Reading in the content areas:Improving classroom instruction. Dubuque, IA: Kendall/Hunt.

McNamara, D. S. ve Kintsch, W. (1996). Learning from texts: Effects of prior knowledge and text coherence. Discourse Processes, 22, 247-288.

Meyer, B. J. (1987). Following the author's top-level organization: An important skill for reading comprehension. Understanding readers' understanding, 59-76.

http://citeseerx.ist.psu.edu/viewdoc/download?doi=10.1.1.709.8864verep=rep1vetype=pdf alınmıştır.

Meyer, B.J.F. (1979). Organizational patterns in prose and their use in reading. M.L. Kamil ve A.J. Moe (Ed.) içinde, Reading research: Studies and applications. Clemson, S.C.: National Reading Conference, Inc.

Meyer, B. J. F., Brandt, D. M. ve Bluth, G. J. (1980). Use of the top-level structure in text: Key for reading comprehension of ninth-grade students. Reading Research Quarterly, 16, 72-103.

Meyer, B. J. F. ve Ray, M. N. (2011). Structure strategy interventions: Increasing reading comprehension of expository text. International Electronic Journal of Elementary Education (Special Issue on Reading Comprehension), 4 (1), 127-152.

Meyer, B.J.F., Wijekumar, K.K. ve Lin, Y. C. (2011). Individualizing a web-based structure strategy intervention for fifth graders' comprehension of nonfiction. Journal of Educational Psychology, 103(1), 140-168.

Oakhill, J., Cain, K. ve Elbro, C. (2014). Understanding and Teaching Reading Comprehension: A Handbook. Routledge. NY.

Özmen, R. (2011). Bir metin yapısı örneği: Evrensel dünya problemlerine ilişkin problem çözüm yapısı. Mustafa Kemal Üniversitesi Sosyal Bilimler Enstitüsü Dergisi 8, 49-62.

Pearson, P. D. ve J. A. Dole. (1987). "Explicit Comprehension Instruction: A Review of Research and a New Conceptualization of Instruction." Elementary School Journal, 88 (2), 151-165.

Pearson, P. D. ve Cervetti, G.N. (2017). The roots of reading comprehension instruction. S.E. Israel (Ed.), Handbook of research on reading comprehension. (2nd.Ed.), (ss.12-56) New York, NY: The Guilford Press.

Pressley, M. (2002). Effective Beginning Reading Instruction. Journal of Literacy Research, 34 (2), 165-188.

Smith, P.L. ve Friend, M. (1986). Training learning disabled adolescents in a strategy for using text structure to aid recall of instructional prose. Learning Disabilities Research, 2(1), 38-44.

Spires, H.A., Gallini, J. ve Riggsbee, J. (1992). Effects of schema-based and text structure-based cues on expository prose comprehension in fourth graders. Journal of Experimental Education, 60(4), 307-320.

Van den Broek, P., Virtue, S., Everson, M. G., Tzeng, Y. ve Sung, Y. (2002). Comprehension and Memory of Science Texts: Inferential Processes and the Construction of a Mental Representation. Otero, J., León, J. A ve Graesser, A. C. (Ed.) içinde, The Psychology of Science Text Comprehension. Mahwah, N.J. : L. Erlbaum Associates, 131-155.

Van Dijk, T. A. ve Kintsch, W. (1983). Strategies of Discourse Comprehension. Academic Press, Inc. New York.

Weisberg, R. ve Balajthy, E. (1989). Transfer effects of instructing poor readers to recognize expository text structure. National Reading Conference Yearbook, 38, 279-286.

Westby, C., Culatta, B., Lawrence, B. ve Hall-Kenyon, K. (2010). Summarizing expository texts. Topics in Language Disorders , 30 (4), 275-287. 
Wijekumar, K.K., Meyer, B.J.F. ve Lei, P. (2012). Large-scale randomized controlled trial with 4th graders using intelligent tutoring of the structure strategy to improve nonfiction reading comprehension. Educational Technology Research and Development, 60(6), 987- 1013.

Williams, J. P. (2003). Teaching text structure to improve reading comprehension. H. L. Swanson, K. R. Harris, ve S. Graham (Ed.) içinde, Handbook of learning disabilities, (ss. 293-305). New York, NY, US: Guilford Press.

Williams, J.P. Hall, K.M. \& Louer, K.D. (2004). Teaching expository text structure to young at-risk learners: Building the basics of comprehension instruction. Exceptionality, 12 (3), 129-144.

Williams, J.P., Hall, K.M., Lauer, K.D., Stafford, K.B., DeSisto, L.A., ve deCani, J.S. (2005). Expository text comprehension in the primary grade classroom. Journal of Educational Psychology, 97(4), 538-550.

Williams, J. P. (2005). Instruction in reading comprehension for primary-grade students: A focus on text structure. The Journal Of Special Education, 30 (1), 6-18.

Williams, J. P., Nubla-Kung, A. M., Pollini, S., Stafford, K. S., Garcia, A. \& Snyder, A. E. (2007). Teaching causeeffect text structure through social studies content to at-risk second graders. Journal of Learning Disabilities, 40 (2), 111-120.

Williams, J.P., Stafford, K.B., Lauer, K.D., Hall, K.M. ve Pollini, S. (2009). Embedding reading comprehension training in content-area instruction. Journal of Educational Psychology, 101(1), 1-20.

Williams, J. P., Pollini, S., Nubla-Kung, A. M., Snyder, A. E., Garcia, A., Ordynans, J. G., \& Atkins, J. G. (2014). An Intervention to Improve Comprehension of Cause/Effect Through Expository Text Structure Instruction. Journal of Educational Psychology. 106 (1), 1-17.

Yazıcı, K. (2006). Hikâye edici metinlerin çözümlenmesinde hikâyenin yüzü stratejisinin kullanımı. Türklük Bilimi Araştırmaları, 1 (20), 229-241.

Yılmaz, M. (2008). Hikâye haritası yönteminin okuduğunu anlamaya etkisi. Erzincan Eğitim Fakültesi Dergisi, 10 (2), 213-225.

\section{Extended Abstract}

In this study, it is aimed to introduce the theoretical structure of the Construction-Integration Model which constitutes the theoretical framework of text structure teaching and the strategies used in practice in this theoretical framework in gaining expository text comprehension skills.

Construction-Integration Model

1970s were the years when psychologists focused on reading processes and a group of theoreticians intensified their studies on text structure. (Pearson \& Cervetti, 2017). One of the models acquired from these studies is Construction-Integration Model (CIM). For this model, mental representation for comprehending the text appears in two stages (Kintsch \& Rawson, 2005; van Dijk \& Kintsch 1983). van Dijk \& Kintsch (1983) named the first stage as textbase. Textbase including, three levels as language, microstructure and macrostructure, provides a set of codded relationships that are important in terms of readers' comprehension with semantic and rhetorical structures. The second model of mental representation is situation model, which is the stage where the information provided by the text meets with the reader's own knowledge.

CIM supports that comprehension process of the text is closely related to the semantic and rhetoric structure of the text. Therefore, it is significant for students to learn text structures and strategies that can be used in literature practices.

\section{Expository Text Structure}

An expository texts aim is to inform students in any kind of subject (Weaver \& Kintsch 1991). For Kintsch (2013), text structures have significant role in evoking mental representation. Expository text structures are textual organizations that include key words to guide readers and enable them to link ideas within the text. (Klingner, Vaughn \& Boardman 2007). Armbruster, Anderson \& Ostertag (1987) identified six types of expository text structures; descriptive, sequential, explanatory, comparative, cause-effect and problem-solving. These text structures like template help us organize the information (Özmen, 2011). This study aims to introduce text structure strategies used in the practices based on theoretical framework of CIM. 


\section{Text Structure Strategy Teaching}

Below given the list of strategies which are commonly used in strategy teaching based on text structure.

\section{Introducing the Text Structure}

Competent readers can easily determine the subject of text and sub-headings only by reviewing the text (Williams, Hall, \& Louer 2004). While the skills of competent readers automatically develop, it is necessary for the students who suffer from reading difficulty to teach this process as strategic behavior and to show them what they will achieve through this review. The Students' knowledge in text structure is important for forming a structure in their minds. Therefore, it is significant to determine the structure of the text. Once they have an information infrastructure, they will easily process the data in textbase.

Key Words

Studies mostly teach students key words which has crucial role in text structure teaching (Spires, Gallini \& Riggsbee, 1992; Weisberg \& Balajthy, 1989) and how to determine the function of these words in text. Recognizing key words is an important strategy that students can see how information is linked in micro level. Readers link the information with key words such as, "because, why, before, after, etc." These words are natural signs that enable us to relate the information in the text. Using these words is quite crucial in terms of forming a consistent text.

Graphic Organizer

Another strategy often used in text structure teaching is graphic organizer. Graphic organizers make it easy to recall the information contained in the text. Furthermore, graphic organizers provide logical relations regarding the information within the structure by allowing students to see these connections. Thus, it is easier to comprehend and recall the text with this visualized information (Özmen, 2011).

\section{Summarizing}

Summarizing strategy helps students to identify the important and detailed information, use the key words, synthetize the information and paraphrasing the texts (Klingner \& others, 2007). Studies based on text structure strategy teaching provide different scaffolds for teaching summarizing strategy. One of these strategies is summarizing paragraph frames. They can be defined as a form including, key words and sentences related to text, yet some important information are missing. It is expected from students to write information that they recall in the gaps by using information about the structure. Another strategy helping students for summarizing is structure questions. The structure questions guide students, while writing summaries and help them focus on necessary information and use it while summarizing.

Consequently, it is important that teachers should use these strategies in their practices to help both normally developing children and disabled children to develop their text comprehensive skills. Scientific studies should be also conducted in our country in this field. 